\title{
Experimental and Numerical Comparison of Reinforced Concrete Gable Roof Beams with Openings of Different Configurations
}

\author{
Maryam Abdul Jabbar Hassan \\ Department of Civil Engineering \\ College of Engineering \\ University of Baghdad \\ Baghdad, Iraq \\ maryemaj123@gmail.com
}

\author{
Amer Farouk Izzet \\ Department of Civil Engineering \\ College of Engineering \\ University of Baghdad \\ Baghdad, Iraq \\ amer.f@coeng.uobaghdad.edu.iq
}

\begin{abstract}
This paper demonstrates an experimental and numerical study aimed at comparing the influence of openings of different configurations on the flexural behavior of reinforced concrete gable roof beams. The experimental program consisted of testing six simply supported gable beams subjected to midpoint concentrated load. The variable which has been investigated in this work was opening's configuration (quadrilateral or circular) with the same upper and lower chords depth. The results indicate improvement in the beams' flexural behavior when circular openings were used compared with that of quadrilateral openings, represented by an increase in ultimate load capacity and a decrease in deflection at the service limit. Also, there was an enhancement in the ductility and rigidity of the beams. The results of the tested beams were verified by a nonlinear finite element program, ABAQUS (2018). Comparisons are presented and good agreement is shown between the predictions of the finite element analysis and the experimental results in terms of failure loads and load-deflection relations.
\end{abstract}

Keywords-reinforced concrete gable roof beam; opening's configuration; chords; numerical analysis

\section{INTRODUCTION}

The presence of openings in gable beams has many advantages such as flexibility, easier handling, and, most importantly, reduced overall weight. Furthermore, concrete has relatively low material cost, good high fire resistance, and low maintenance cost, therefore reinforced concrete gable beams can be used as a good alternative option instead of steel sections to support warehouse roofs, industrial buildings, and airplane hangars. But the insertion of openings in a solid beam directly affects beam behavior resulting in a more complicated behavior as the openings would essentially cause a sudden drop in the beam cross section dimensions. At the same time, the corners of the openings would be subjected to a high concentration of stress that could result in extensive cracking which is inadmissible from both esthetic and durability points of view. In addition, the presence of the openings would reduce the overall stiffness of the beam, which may result in extreme deflections under service loads. The design of these beams therefore, requires special treatment to control the crack width and to avoid probable early failure of the beam $[1,2]$.

Researches on the reinforced concrete beams with openings began in the early ' 60 s [3-5]. Extensive study has been carried out in [6] on concrete beams with large openings using nonlinear Finite Element Analysis and taking into consideration assumptions for the geometric constraints. The results show that openings near the supports can be used to perform detailed calculations for shear force distribution in both chords. In [7], the influence of circular openings on the structural performance of concrete beams was examined by testing 9 perforated normal strength concrete beams and 5 perforated high strength concrete beams, in addition to a reference solid normal strength concrete beam under two-point loads. The main findings were that both ultimate strength reduction and cracking pattern were magnified in the normal concrete beams, when the opening's diameter exceeded the one-third of the beam's depth. The diameter and the opening place were the main parameters affecting the strength of the beam.

Three-dimensional Finite Element Model that can capture the flexural performance of concrete beams with one rectangular opening was proposed in [8]. A thorough validation was undertaken using several models including one rectangular transverse opening showing a good agreement between numerical and experimental results. The main investigated variables to understand their effect on the structural response of the member were: concrete compressive strength, reinforcement ratio, and opening dimensions. The numerical solution showed that the ultimate strength of the beam and the post-cracking stiffness rise with the increase of concrete compressive strength, or increase of bottom reinforcement amount and decrease with increasing opening size. In [9], a new theory of nonlinear three-dimensional elastic damage to simulate reinforced concrete elements was proposed. More attention was paid to simulate perforated reinforced concrete beams' nonlinear behavior based on thermodynamic basis. The developed theoretical approach considers nonlinear elastic behavior and concrete materials' deteriorated state. To validate 
the suggested model, a comparison was made with experimental results and a good agreement was reached. In [10], a numerical investigation of the effects of circular- shaped openings on the performance of reinforced concrete beams with finite element method (FEM) has been suggested. The finite element package ANSYS 14.0 was used to simulate simply supported concrete beams with circular openings having different diameters at various positions. Seven models were numerically replicated with ANSYS. The main finding was that the location of the opening has a significant effect on the behavior of the model. Locating the opening near the supports resulted in dropping of the maximum strength capacity of the model by $32 \%$ in respect to the solid beam with less significant influence on the maximum strength when the circular-shaped opening was located at the center of the span. In [11], a numerical study explored the structural behavior of reinforced concrete beams with circular openings via finite element method using ABAQUS. The main variables were opening size and location. Seven beams were tested under three-point loading. The results showed that an increase of the opening size decreases the ultimate strength of the beam and increases its maximum deflection. Placing of the opening in the shear zone decreased the ultimate strength by about $26 \%$ and $36 \%$ and increased maximum deflection by about $4 \%$ and $22 \%$ compared to the reference beam. On the other hand, for beams with the opening located in the flexure zone, the ultimate strength was decreased by about $6 \%$ and $13 \%$ and the maximum deflection was increased by about $1.5 \%$ and $19.7 \%$. Therefore, the optimum location for the openings in the reinforced concrete beam was found to be the flexural zone.

\section{EXPERIMENTAL PROGRAM}

The experimental program of this study was executed by manufacturing and testing 6 simply supported reinforced concrete gable roof beams under monotonic static loading at mid span until failure. The studied variable was the opening's configuration (quadrilateral or circular) with the same upper and lower chords depth [12].

\section{A. Specimen Details}

The test specimens, including the reference beam without openings (solid) and the other 5 beams with eight (quadrilateral or circular) openings, had an overall length of $3000 \mathrm{~mm}$, width of $100 \mathrm{~mm}$, and height $400 \mathrm{~mm}$ at the center and $250 \mathrm{~mm}$ at the ends as exhibited in Table I. All beams had the same details of reinforcement as shown in Figure 1. The beams were tested with an overall clear span of $2800 \mathrm{~mm}$. The specimens were divided into three groups ( $\mathrm{A}, \mathrm{B}$, and $\mathrm{C})$. These groups were classified as mentioned, according to the variable that have been used in this study (Table I).

\section{B. Material Properties}

Normal concrete has been used to cast the beams. The properties of concrete (compressive strength, splitting tensile strength, and modulus of elasticity) were determined using cylindrical steel molds (with 150 and $300 \mathrm{~mm}$ diameter and height respectively). The diameters of used steel reinforcement bars were: $4,6,12 \mathrm{~mm}$ and the properties of the average yield, ultimate stresses, and modulus of elasticity were determined according to the standard tests of steel reinforcements bars. The properties of normal concrete and steel reinforcements used in this work are given in Table II.

(a)

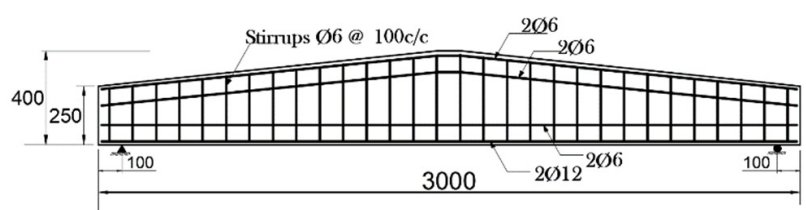

(b)

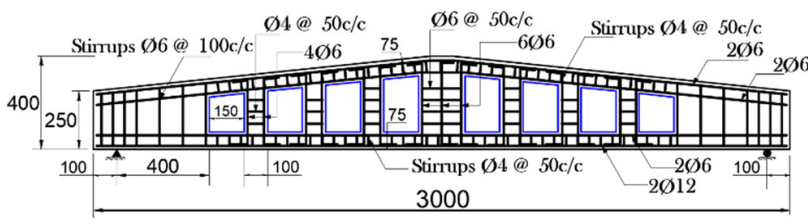

(c)

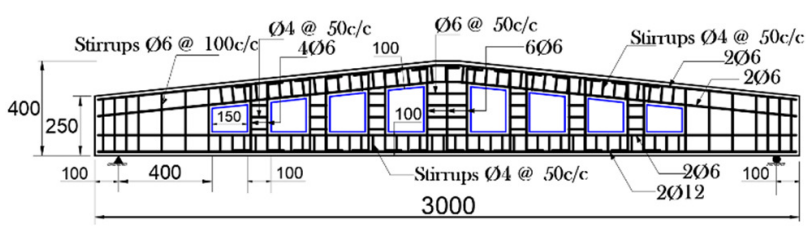
Ø4@ $50 \mathrm{c} / \mathrm{c}$

(6)

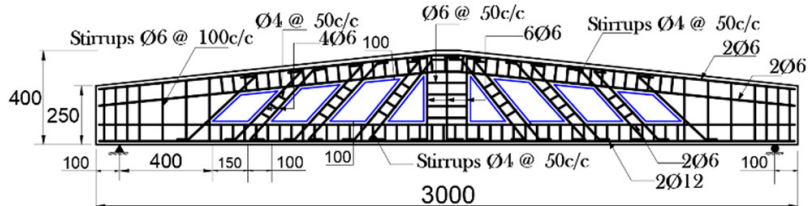

(d)

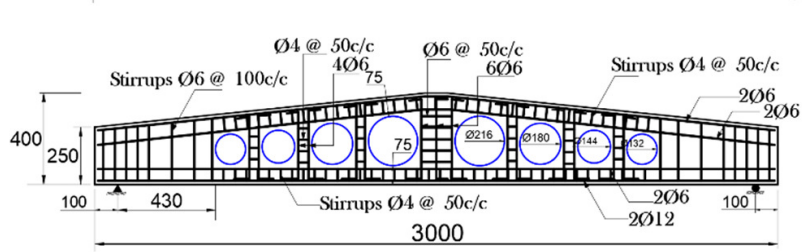

(f)

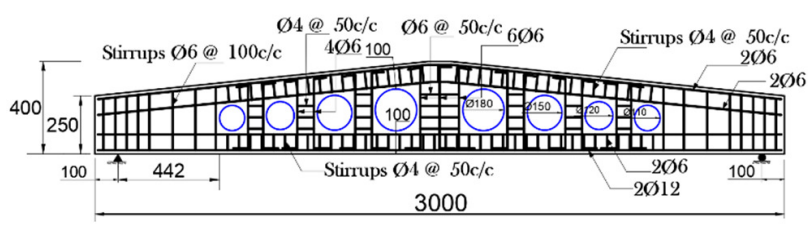

Fig. 1. Details of beam specimens (all dimensions are in mm): (a) Beam GB, (b) Beam GTH8, (c) Beam GT8, (d) Beam GP8, (e) Beam GC1, (f) Beam GC2

\section{Setup and Testing Procedure}

Figure 2 exhibits a schematic shape of the test setup. The test rig frame dimensions were $5.45 \mathrm{~m}$ width and $3.00 \mathrm{~m}$ height. The beams were simply supported by steel rollers with a thick steel plate. The left one was welded to the beneath bearing plate to simulate hinge support whereas the other one was not. In the case of beams with multi openings, the applying load is preferred to be on the post nodes. To eliminate the difference in load due to the difference in openings' size and locations, the load was applied on a thick $100 \mathrm{~mm} \times 100 \mathrm{~mm}$ bearing steel plate positioned at the tapered crest end of the gable beam which was flatted horizontally. A hydraulic jack of 50ton capacity was used to apply load on the beams. The applied load was controlled by using a load cell with a digital load reader. The 
load was applied with an increment of $2 \mathrm{kN}$. Dial gauges were used for measuring the vertical deflections at a distance of $150 \mathrm{~mm}$ from support and at mid-span. Also the longitudinal generated strain at the surface of the concrete and reinforcing steel bar due to the applied loads was measured by strain gauges. The beams were loaded up to failure, the deflection and generated strains were measured, the propagation of cracks was marked and the crack widths measured at different load levels.

TABLE I. DETAILS OF THE TESTED BEAMS

\begin{tabular}{|c|c|c|c|c|c|c|}
\hline Group & Beam mark & Shape of openings & Number of openings & $\begin{array}{c}\text { Total area of openings } \\
\left(\mathrm{mm}^{2}\right)\end{array}$ & $\begin{array}{c}\text { Upper chord height } \\
(\mathrm{mm})\end{array}$ & $\begin{array}{c}\text { Lower chord height } \\
(\mathrm{mm})\end{array}$ \\
\hline Ref. beam & GB & ------ & ----- & ----- & ------ & ------ \\
\hline \multirow{2}{*}{$\mathbf{A}$} & GTH8 & Trapezoidal & 8 & 234000 & 75 & 75 \\
\hline & $\mathrm{GC1}$ & Circular & 8 & 184200 & 75 & 75 \\
\hline \multirow{2}{*}{ B } & GT8 & Trapezoidal & 8 & 174000 & 100 & 100 \\
\hline & GC2 & Circular & 8 & 128000 & 100 & 100 \\
\hline \multirow[t]{2}{*}{$\mathbf{C}$} & GP8 & $\begin{array}{l}\text { Trapezoidal with } \\
\text { inclined posts }\end{array}$ & 8 & 151000 & 100 & 100 \\
\hline & GC2 & Circular & 8 & 128000 & 100 & 100 \\
\hline
\end{tabular}

TABLE II. MATERIAL PROPERTIES

\begin{tabular}{|c|c|c|c|c|c|}
\hline Material & Diameter $(\mathbf{m m})$ & Yield stress (MPa) & Compressive strength (MPa) & Ultimate tensile strength (MPa) & Modulus of elasticity (GPa) \\
\hline Concrete & ----- & ----- & 31 & 3.5 & 27 \\
\hline \multirow{3}{*}{ Steel } & 4 & 370 & ----- & 567 & 629 \\
\cline { 2 - 6 } & 6 & 550 & ----- & 200 \\
\cline { 2 - 6 } & 12 & 600 & ----- & 677 \\
\hline
\end{tabular}

TABLE III. TEST RESULTS

\begin{tabular}{|c|c|c|c|c|c|c|}
\hline Group & Beam mark & $P_{\mathrm{cr}}(\mathrm{kN})$ & $\begin{array}{l}\text { Ultimate load } P_{u} \\
(k N)\end{array}$ & $\begin{array}{c}\text { Decreasing ratio of } \\
\text { total volume } \% 1\end{array}$ & $\begin{array}{c}\text { Decreasing ratio of } \\
\mathbf{P}_{\mathrm{u}} \%{ }^{2}\end{array}$ & Crack and Failure Mode \\
\hline Ref. beam & GB & 18 & 90 & ------ & ------ & Flexural tension failure \\
\hline \multirow{2}{*}{$\mathbf{A}$} & GTH8 & 14 & 76.8 & 23.82 & 14.67 & $\begin{array}{l}\text { Flexural tension failure and beam- } \\
\text { type failure around openings }\end{array}$ \\
\hline & $\mathrm{GC} 1$ & 14 & 81.5 & 8.35 & 9.44 & $\begin{array}{l}\text { Flexural tension failure and beam- } \\
\text { type failure around openings }\end{array}$ \\
\hline \multirow{2}{*}{ B } & GT8 & 14 & 80.2 & 17.71 & 10.89 & $\begin{array}{l}\text { Flexural tension failure and beam- } \\
\text { type failure around openings }\end{array}$ \\
\hline & $\mathrm{GC} 2$ & 14 & 86 & 13.03 & 4.44 & $\begin{array}{l}\text { Flexural tension failure and beam- } \\
\text { type failure around openings }\end{array}$ \\
\hline \multirow{2}{*}{$\mathbf{C}$} & GP8 & 18 & 83.8 & 15.37 & 6.89 & $\begin{array}{l}\text { Flexural tension failure and beam- } \\
\text { type failure around openings }\end{array}$ \\
\hline & $\mathrm{GC} 2$ & 14 & 86 & 13.03 & 4.44 & $\begin{array}{l}\text { Flexural tension failure and beam- } \\
\text { type failure around openings }\end{array}$ \\
\hline
\end{tabular}

(1) Decreasing ratio of total volume related to reference beam GB

$$
\text { (2) } \frac{\sigma_{\omega \alpha}(\varepsilon s)-p_{\alpha \alpha}(\operatorname{sem})}{\sigma_{\omega \alpha}(\varepsilon \varepsilon)}+100
$$

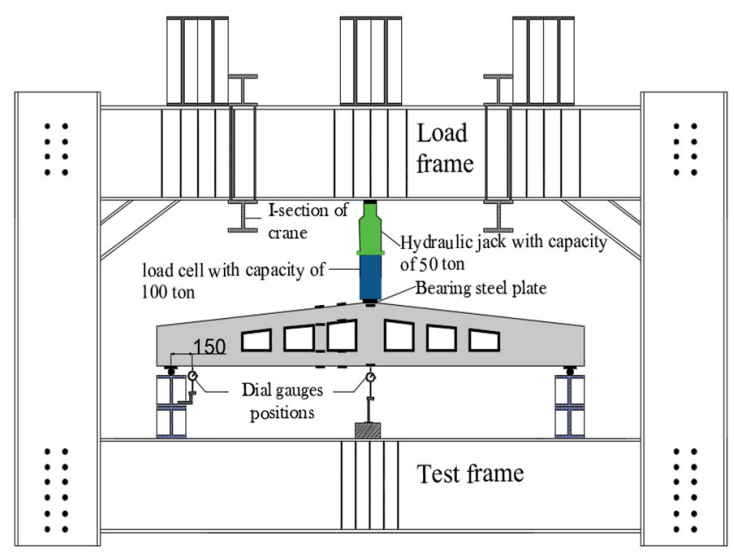

Fig. 2. Test setup

\section{EXPERIMENTAL RESULTS AND DISCUSSION}

\section{A. Cracking, Failure Loads, and Mode of Failure}

First cracking load is known as the applied load at crack appearance in the tension zone of the beam. It was recorded experimentally as the first observed crack by a microscope. The test showed that the first crack load of the solid beam (reference beam) was $18 \mathrm{kN}$ while it ranged from 14 to $18 \mathrm{kN}$ for the beams with openings. So, it can be concluded that the insertion of openings had a little effect on cracking formation. Results exhibit that the presence of openings in a gable roof beam reduces its ultimate load capacity, due to sudden drop in the beam's cross section dimensions. It can be noticed that the decreasing ratio of ultimate strength ranged between $(4.44 \%$ $14.67 \%$ ) related to the reference beam which can be considered comparatively little. This might be attributed to the efficient design represented by sufficient quantity of reinforcements and 
using short stirrups in the top and bottom chords to prevent frame-type shear failure [2]. Conversely, the experiments indicated that the reference beam (GB) failed in the tensioncontrolled flexural mode after the yielding of tension steel. A limited number of diagonal cracks in the vicinity of supports did not influence the failure. The beams with openings failed in the tension-controlled flexural mode due to the formation of several flexural cracks in the tension zone and finally crushing of concrete near the loading point. The type of cracks at the corners of the openings was beam-type failure [2], and it can be observed that cracks at the corner of openings did not cause clear reduction in the load-carrying capacity of the beam. Table III indicates loads and modes of failure, while Figure 3 shows the crack patterns of the tested beams.

(a)

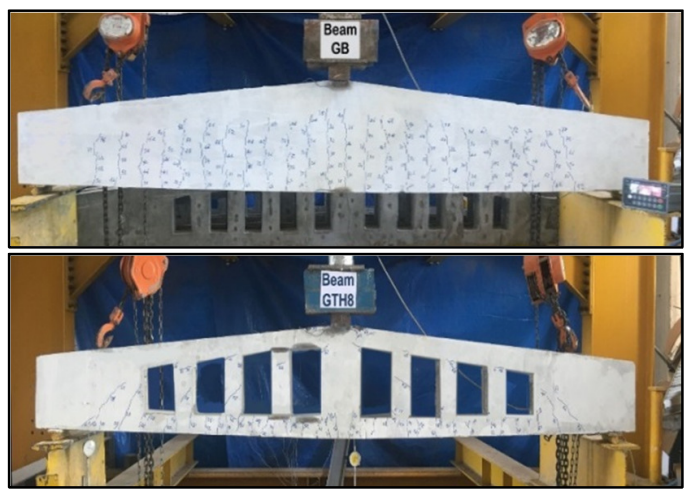

(c)

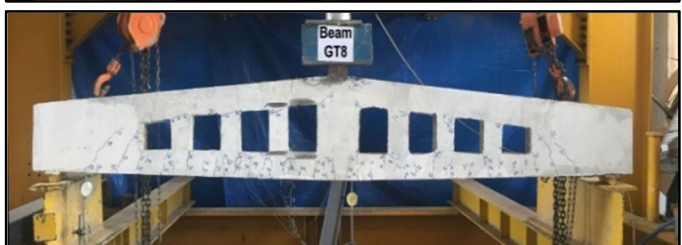

(d)

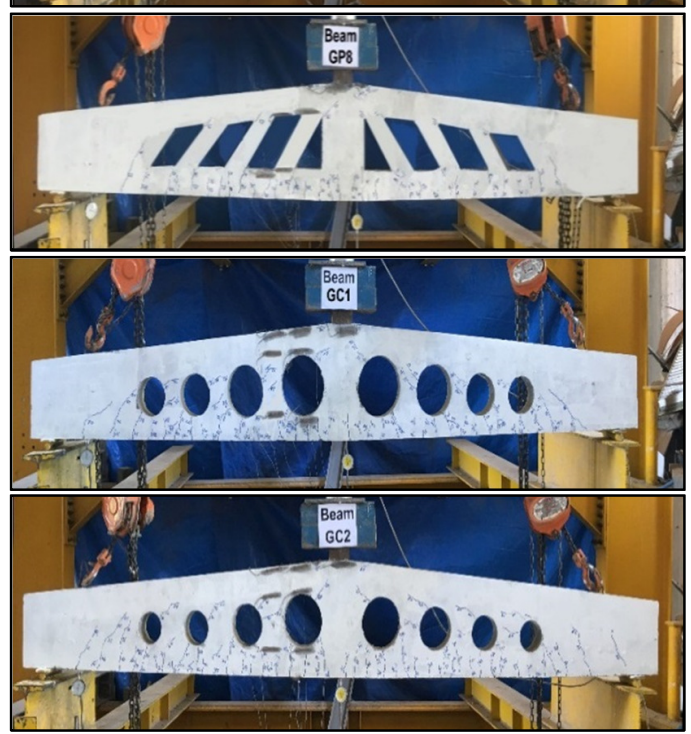

Fig. 3. Crack patterns: (a) Beam GB, (b) Beam GTH8, (c) Beam GT8, (d) Beam GP8, (e) Beam GC1, (f) Beam GC2

\section{B. Load-Deflection Relationship}

Mid-span deflection at different loading stages $(20,50 \mathrm{kN}$, and ultimate load) are summarized in Table IV and Figure 4. Results exhibit that the insertion of openings in a reinforced concrete beam usually increases its deflection due to the abrupt change in the cross-sectional dimensions which leads to reduced stiffness of the beam and thus causes excessive deflection. The increasing ratio of ultimate mid span deflection ranged between $42.32 \%$ and $56.85 \%$. Figure 4 demonstrates the deflection response due to the applied load for Groups A, B, and $\mathrm{C}$. The results indicate an increase in ultimate load capacity for beams with circular openings compared to beams with quadrilateral openings and the increase ratios were: $6.1 \%$ for beam GC1 related to beam GTH8 (Group A), 7.23\% for beam GC2 related to beam GT8 (Group B), and 2.6\% for beam GC2 related to beam GP8 (Group C). On other hand, the deflections at different loading stages are:

\section{1) At $20 \mathrm{kN}$ Lload}

- Group A: the deflection for beam GC1 is less than the deflection of beam GTH8 by $22.61 \%$.

- Group B: the deflection for beam GC2 is less than the deflection of beam GT8 by $15.52 \%$.

- Group C: the deflection for beam GC2 is less than the deflection of beam GP8 by $3.41 \%$.

2) At $50 \mathrm{kN}$ Load

- Group A: the deflection for beam GC1 is less than the deflection of beam GTH8 by $18.3 \%$.

- Group B: the deflection for beam GC2 is less than the deflection of beam GT8 by $16.9 \%$.

- Group C: the deflection for beam GC2 is less than the deflection of beam GP8 by $11.66 \%$.

3) At Ultimate Load

- Group A: the deflection for beam GC1 is less than the deflection of beam GTH8 by $1.8 \%$.

- Group B: the deflection for beam GC2 is higher than the deflection of beam GT8 by $6.82 \%$.

- Group C: the deflection for beam GC2 is slightly higher than the deflection of beam GP8 by only $0.3 \%$.

The results clarified that circular openings improve the ultimate load carrying capacity and flexural behavior, in comparison with quadrilateral openings, because the nature of the circular configuration reduces the possible stress concentration around the opening. Also the total area of circular openings is smaller as clarified in Table III.

\section{Ductility and Rigidity}

Ductility index $(\mu)$ is mostly defined as the ability of the beam to sustain additional deformation before failure. Mathematically it is the ratio of mid-span deflection at $85 \%$ of ultimate load to that at yielding of the tension reinforcement [13]. This value is tabulated in Table $\mathrm{V}$, in addition to the rigidity value $(\mathrm{k})$ which corresponds to the initial slope of the 
load-deflection curves (Figure 4). According to Table V, the highest values of $\mu$ are recorded for beams with circular openings (GC1 and GC2) which significantly exceeded the reference beam. Also, the increasing number of openings led to decrease $\mu$ values, the reason might be the energy absorption capacity of the beam with circular openings which significantly exceeded the energy absorption capacities of solid beam and of the beam with quadrilateral openings. On the other hand, the provision of openings results in significant reduction of the rigidity of a beam. Table $\mathrm{V}$ indicates that the beams with quadrilateral openings had smaller rigidities compared to the beams with circular openings. This can be primarily attributed to the smaller total area of circular openings. Reduction in the stresses due to the lack of sharp corners in circular openings may have resulted in a more rigid flexural behavior in theses beams.

TABLE IV. DEFLECTION AT VARIOUS LOADING STAGES OF THE TESTED BEAMS

\begin{tabular}{|c|c|c|c|c|c|c|c|}
\hline \multirow[b]{2}{*}{ Group } & \multirow[b]{2}{*}{ Beam mark } & \multicolumn{2}{|c|}{ At $20 \mathrm{kN}$} & \multicolumn{2}{|c|}{ At $50 \mathrm{kN}$} & \multicolumn{2}{|c|}{ At $P_{u}(k N)$} \\
\hline & & $\begin{array}{c}\text { Deflection } \\
(\mathrm{mm})\end{array}$ & $\begin{array}{c}\text { Increasing ratio of } \\
\text { deflection } \%\end{array}$ & $\begin{array}{l}\text { Deflection } \\
(\mathrm{mm})\end{array}$ & $\begin{array}{l}\text { Increasing ratio } \\
\text { of deflection \% }\end{array}$ & $\begin{array}{c}\text { Deflection } \\
(\mathrm{mm})\end{array}$ & $\begin{array}{l}\text { Increasing ratio } \\
\text { of deflection \% }\end{array}$ \\
\hline Ref. beam & GB & 2.62 & ----- & 7.93 & ----- & 16.80 & $\begin{array}{l}---- \\
\end{array}$ \\
\hline \multirow{2}{*}{$\mathbf{A}$} & GTH8 & 3.67 & 40.08 & 11.33 & 42.88 & 26.35 & 56.85 \\
\hline & GC1 & 2.84 & 8.40 & 9.26 & 16.77 & 25.88 & 54.05 \\
\hline \multirow{2}{*}{ B } & GT8 & 3.35 & 27.86 & 10.48 & 32.16 & 23.91 & 42.32 \\
\hline & GC2 & 2.83 & 8.02 & 8.71 & 9.84 & 25.54 & 52.02 \\
\hline \multirow{2}{*}{ C } & GP8 & 2.93 & 11.83 & 9.86 & 24.34 & 25.46 & 51.55 \\
\hline & GC2 & 2.83 & 8.02 & 8.71 & 9.84 & 25.54 & 52.02 \\
\hline
\end{tabular}

TABLE V. DUCTILITY AND RIGIDITY OF THE TESTED BEAMS

\begin{tabular}{|c|c|c|c|c|c|c|c|}
\hline \multirow[b]{2}{*}{ Group } & \multirow[b]{2}{*}{$\begin{array}{l}\text { Beam } \\
\text { mark }\end{array}$} & \multicolumn{4}{|c|}{ Deformation ductility, $\mu$} & \multicolumn{2}{|c|}{ Rigidity (kN/m) } \\
\hline & & $\Delta_{0.850 f}$ Pult & $\Delta_{\text {yielding }}$ & $\mu$ & $\frac{\mu_{\text {beam }}}{\mu_{\text {beam GB }}}$ & $\mathbf{k}$ & $\frac{\mathbf{k}_{\text {beam }}}{\mathbf{k}_{\text {beam GB }}}$ \\
\hline Ref. beam & GB & 13.01 & 4.57 & 2.85 & 1.00 & 9.26 & 1.00 \\
\hline \multirow{2}{*}{ A } & GTH8 & 17.38 & 5.87 & 2.96 & 1.04 & 4.96 & 0.54 \\
\hline & $\mathrm{GC1}$ & 14.00 & 4.11 & 3.41 & 1.2 & 8.00 & 0.86 \\
\hline \multirow{2}{*}{ B } & GT8 & 15.88 & 6.39 & 2.48 & 0.87 & 6.83 & 0.74 \\
\hline & GC2 & 14.28 & 4.26 & 3.35 & 1.18 & 8.48 & 0.92 \\
\hline \multirow{2}{*}{$\mathbf{C}$} & GP8 & 14.20 & 5.57 & 2.55 & 0.89 & 7.27 & 0.79 \\
\hline & GC2 & 14.28 & 4.26 & 3.35 & 1.18 & 8.48 & 0.92 \\
\hline
\end{tabular}
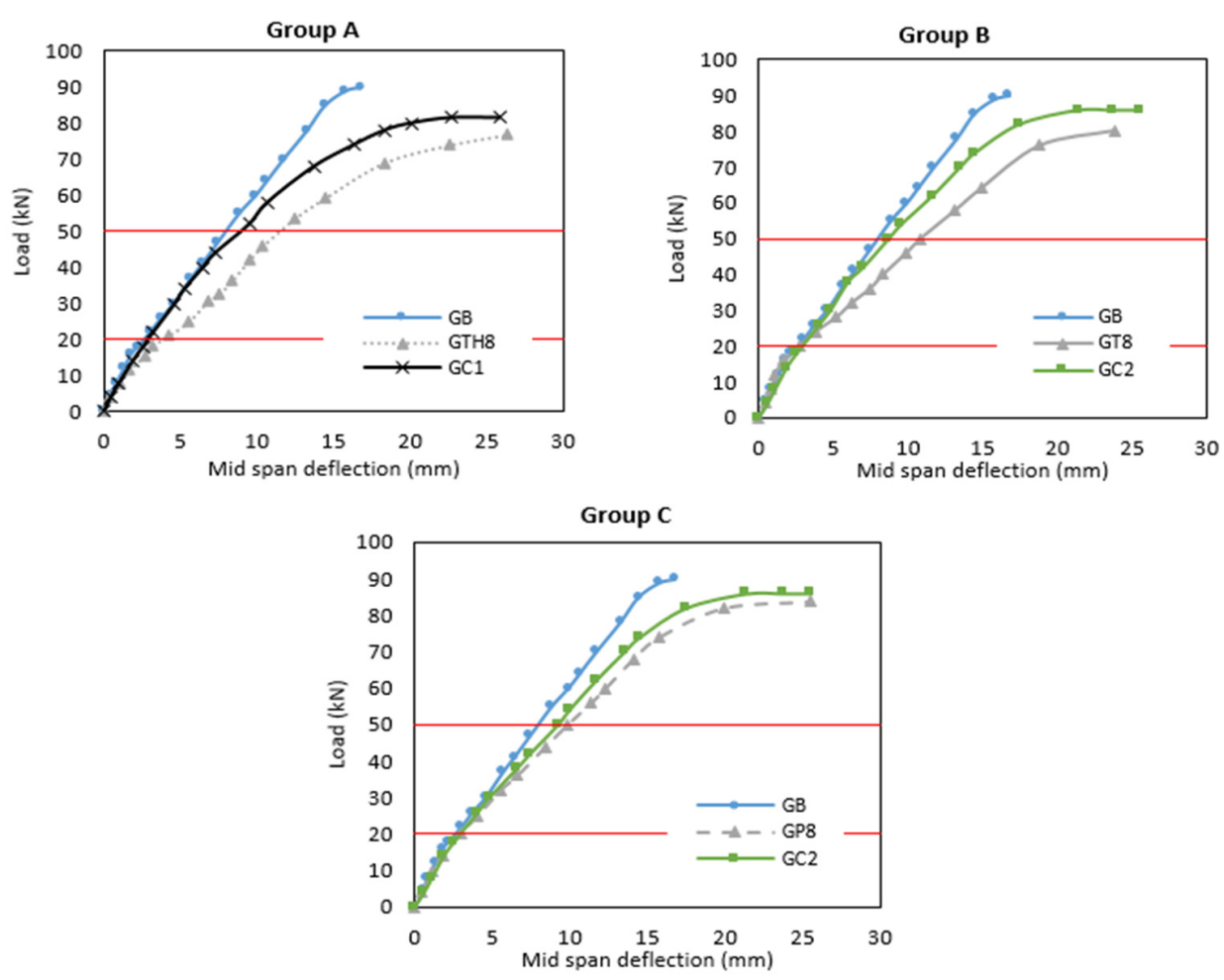

Fig. 4. Load-mid span deflection relationships 


\section{FINITE ELEMENT MODELING}

\section{A. Element Types, Boundary, and Loading Conditions}

The characters of the finite elements types used in modeling each of the tested beams by ABAQUS program are summarized in Table VI. Each element type in the present model has been used to represent a specified constituent of each of the tested beams [14].

TABLE VI. DESCRIPTION OF THE USED ELEMENTS

\begin{tabular}{|c|c|c|}
\hline Beam Components & Family & Elem ent characteristics \\
\hline $\begin{array}{c}\text { Concrete and bearing } \\
\text { steel plates }\end{array}$ & 3D Stress & $\begin{array}{c}\text { C3D8R: An 8-node linear brick, } \\
\text { reduced integration, hourglass control }\end{array}$ \\
\hline $\begin{array}{c}\text { Steel reinforcing bars } \\
\text { (long. top, long. } \\
\text { bottom, and shear } \\
\text { reinforcement) }\end{array}$ & Truss & T3D2: A 2-node linear 3-D truss \\
\hline
\end{tabular}

In order to avoid stress concentration at supports and loading point, steel plates with dimensions of $100 \mathrm{~mm} \times 100 \mathrm{~mm} \times 20 \mathrm{~mm}$ were added (full contact element with full bond between bearing plates and the specimen). The simple support at the left side of the beam has been modeled as a hinge by constraining a single line of bearing plate nodes over the width of the beam soffit in the $\mathrm{x}$ - and y-directions support (i.e. $\mathrm{U}_{\mathrm{x}}=\mathrm{U}_{\mathrm{y}}=0$ ) while allowing rotation about the $\mathrm{x}$-axis. The other support has been modeled as a roller by constraining the $y$-direction $\left(\mathrm{U}_{\mathrm{y}}=0\right)$ and allowing longitudinal displacements and rotations about the $\mathrm{x}$-plane axis. The load was applied as a distributed pressure on the loading plate, the applied boundary and loading conditions are shown in Figure 5 .

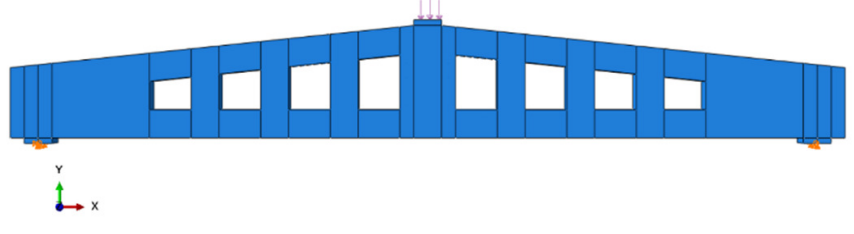

Fig. 5. Boundary and loading conditions used in the analysis

\section{B. Reinforcement, Meshing and Analysis of the Model}

The reinforcement is assumed to be fully embedded into concrete. The general view of the numerical model of reinforcement is displayed in Figure 6.

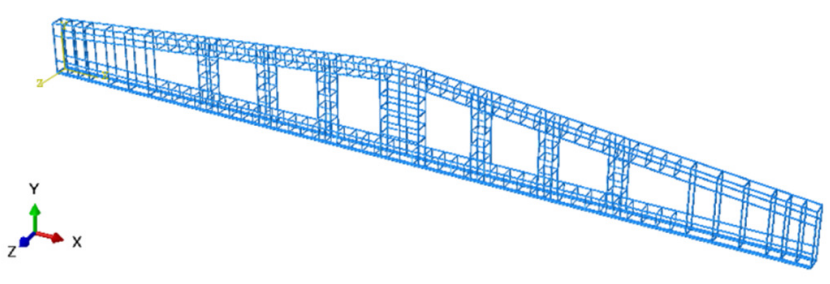

Fig. 6. Numerical reinforcement model

The aggregates used in the experimental work had a maximum size of $10 \mathrm{~mm}$. Since the macro-scale behavior of concrete depends on the aggregate size, the mesh size needed to be greater than the maximum aggregate size [15] for accurate results, therefore a mesh size of $25 \mathrm{~mm}$ with an aspect ratio of 1 was chosen for the analysis. The meshed model is demonstrated in Figure 7.

ABAQUS software allows selecting the kind of analysis required to perform the model with specifying step increment (automatic step increment or fixed step increment). Each analysis step in ABAQUS is divided into several increments. The type of analysis used depends on the loading conditions and response you wish to detect. The presented model, static analysis type and fixed step increment are utilized.

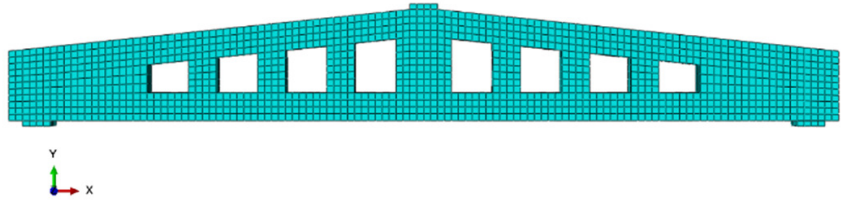

Fig. 7. Numerical meshed model

\section{RESULT COMPARISON}

\section{A. Failure Loads and Ultimate Deflection}

Table VII shows a comparison between the failure loads and mid-span deflection obtained from the finite element models and from the experimental work at failure stage for all beams under static test [12]. A good agreement was obtained between ultimate loads and deflection of numerical models and experimentally tested beams, where the value of the average for $\left(P_{u}\right) /\left(P_{u}\right)_{\text {Exp }}$ was 1.03 , whilst the value of the average for $\mathrm{W}_{F E} / \mathrm{W}_{E x p}$ was 0.95 , therefore the finite element analysis can be considered a good tool to describe the flexural behavior of the tested beams.

TABLE VII. COMPARISON OF FAILURE LOAD AND MID-SPAN DEFLECTION

\begin{tabular}{|c|c|c|c|c|c|c|c|}
\hline \multirow{2}{*}{ Group } & \multirow{2}{*}{$\begin{array}{l}\text { Beam } \\
\text { mark }\end{array}$} & \multicolumn{2}{|c|}{ Failure Load (kN) } & \multirow{2}{*}{$\left(P_{u}\right)_{F E} /\left(P_{u}\right)_{E x p}$} & \multicolumn{2}{|c|}{ Mid-span deflection (mm) } & \multirow{2}{*}{$W_{F E} / W_{E x p}$} \\
\hline & & $\left(P_{u}\right)_{F E}$ & $\left(P_{u}\right)_{E x p}$ & & WFE & WExp & \\
\hline Ref. beam & GTH8 & 81.97 & 76.8 & 1.07 & 24.66 & 26.35 & 0.94 \\
\hline \multirow{2}{*}{ A } & GT8 & 83.13 & 80.2 & 1.04 & 20.83 & 23.91 & 0.87 \\
\hline & GC1 & 84.72 & 81.5 & 1.04 & 27.04 & 25.88 & 1.04 \\
\hline \multirow{2}{*}{ B } & GT8 & 83.13 & 80.2 & 1.04 & 20.83 & 23.91 & 0.87 \\
\hline & GC2 & 87.13 & 86 & 1.01 & 25.88 & 25.54 & 1.01 \\
\hline \multirow{3}{*}{$\mathrm{C}$} & GP8 & 85.20 & 83.8 & 1.02 & 23.72 & 25.46 & 0.93 \\
\hline & GC2 & 87.13 & 86 & 1.01 & 25.88 & 25.54 & 1.01 \\
\hline & & \multicolumn{2}{|c|}{ Mean } & 1.03 & \multicolumn{2}{|c|}{ Mean } & 0.95 \\
\hline
\end{tabular}



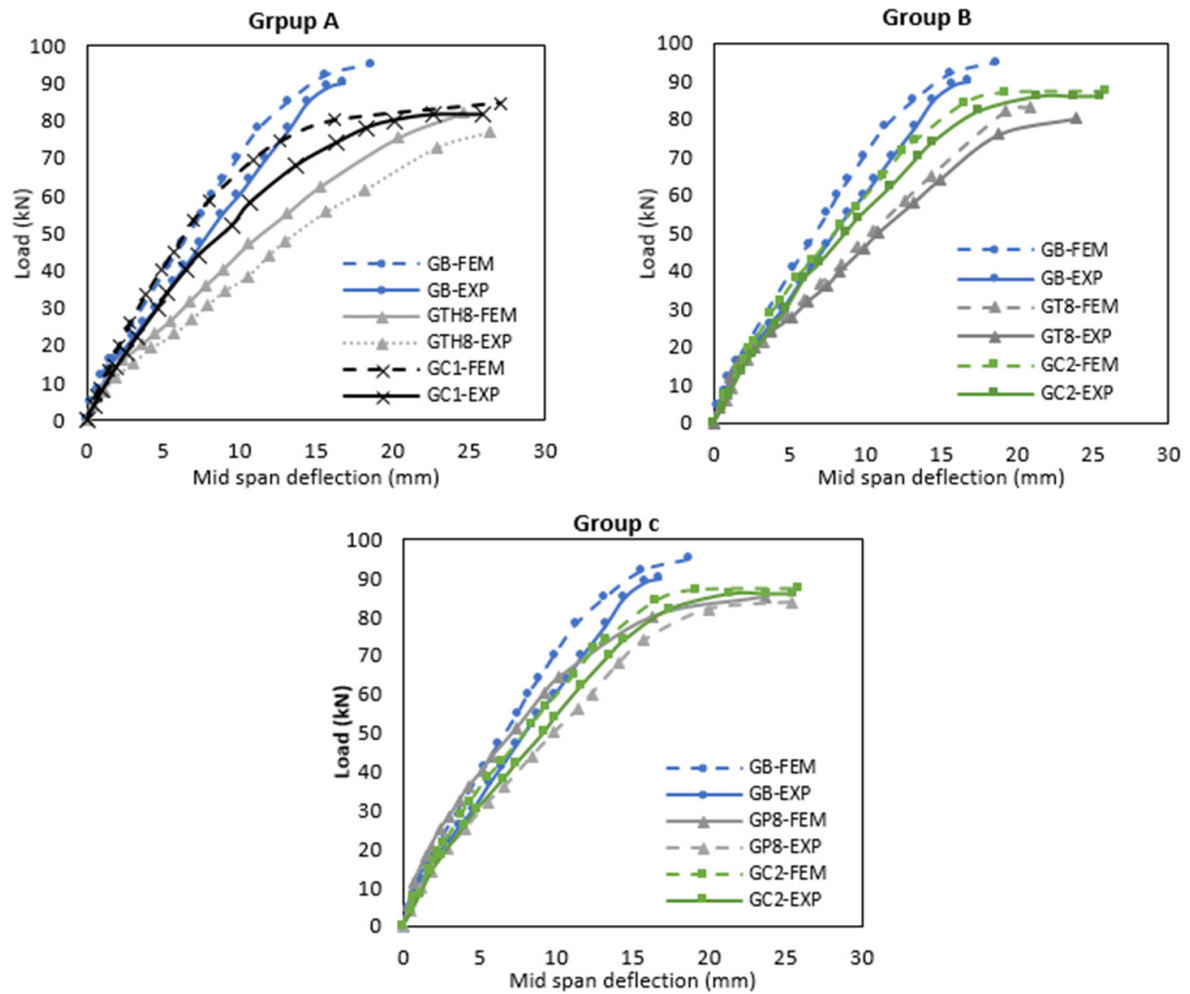

Fig. 8. Predicted and experimental load-mid span deflection relations

\section{B. Load-Deflection Relationship}

The results found from the FE analysis for the load versus deflection relation for static analysis models are compared with the experimental results in Figure 8. It can be observed that the behavior of load-deflection curves obtained from FE analysis is slightly higher than the real experimental work. In other words, the numerical models were stiffer than the experimental data in both linear and nonlinear regions. This is not strange since the finite element method deals with the model member as a rigid body, which is more stiff and stronger than the actual body, and also due to the assumed perfect bond between concrete and steel reinforcement, but anyhow there was a good agreement between them.

\section{CONCLUSIONS}

Provision of openings in a gable roof reduces their weight which and can be cast in place or manufactured in precast factories and transmitted to be used as supporting members for long span roofs. So, the provision of openings in a gable beam offers several advantages such as lightweight, ease of handling and erection, and geometric flexibility. Based on the current study the following can be concluded:

- Using circular openings instead of quadrilateral ones improves flexural behavior of the beams represented by an increase in ultimate load capacity and decrease in deflection at service limit. Also it increases both ductility and rigidity.

- Using of inclined posts for openings instead of vertical ones has been instrumental in improving flexural behavior and reducing the difference between them and beams with circular openings in terms of maximum load capacity, deflection and rigidity.

- Finite element analysis with ABAQUS (2018) software was used to validate the results of the tested beams. Comparisons were presented and good agreement was shown between the predictions of the finite element model and the experimental results in terms of failure loads and load-deflection relations.

- The average ratio of ultimate loads and deflection of numerical models to the experimentally tested beams was 1.03 and 0.95 , respectively. Therefore, finite element analysis can be considered a good tool to describe the flexural behavior of the tested beams.

\section{REFERENCES}

[1] M. A. Mansur, K. H. Tan, Concrete beams with openings: analysis and design, CRC Press, 1999

[2] V. N. Baykov, E. E Seagal, Reinforced concrete structures, Stroyizdat, 1991

[3] S. A. Salam, "Beams with openings under different stress conditions", in: Proceedings of the 3rd Conference on Our World in Concrete and Structures, CI Premier, 1977

[4] M. A. Mansur, K. H. Tan, S. L. Lee, "Design method for reinforced concrete beams with large openings", Journal Proceedings, Vol. 82, No. 4, 1985

[5] M. A. Mansur, Y. F. Lee, K. H. Tan, S. L. Lee, "Tests on RC continuous beams with openings", Journal of Structural Engineering, Vol. 117, No. 6, pp. 1593-1606, 1991

[6] S. Ehmann, M. Schnellenbach-Held, "Behaviour and design of reinforced concrete beams with large openings", in: Fracture Mechanics of Concrete Structures, pp. 903-909, Swets \& Zeitlinger, 2001 
[7] J. V. Amiri, M. H. ALibygie, "Effect of small circular opening on the shear and flexural behavior and ultimate strength of reinforced concrete beams using normal and high strength concrete", 13th World Conference on Earthquake Engineering, Vancouver, Canada, Paper No. 3239, August 1-6, 2004

[8] A. S. Al-Shaarbaf, N. A. M. J. Al-Bayati, D. I. A. Al-Kaisy, "Nonlinear finite element analysis of reinforced concrete beams with large opening under flexure", Engineering and Technology Journal, Vol. 25, No. 2, pp. 210-228, 2007

[9] H. Madkour, K. Ahmed, "Three-dimensional modelling for reinforced concrete beams with openings based on nonlinear elastic-damage theory", Journal of Engineering Sciences, Vol. 35, No. 1, pp. 9-27, 2007

[10] N. H. Saksena, P. G. Patel, "Effects of the circular openings on the behavior of concrete beams without additional reinforcement in opening region using fem method", International Journal of Advanced Engineering Technology, Vol. 4, No. 2, 2013

[11] A. A. F. Shubbar, H. Alwan, E. Y. Phur, J. McLoughlin, A. Al-Khaykan, "Studying the structural behavior of RC beams with circular openings of different sizes and locations using FE method", World Academy of Science, Engineering and Technology, International Journal of Structural and Construction Engineering, Vol. 11, No. 7, pp. 849-852, 2017

[12] M. A. J. Hassan, A. F. Izzet, "Serviceability of reinforced concrete gable roof beams with openings under static loads", Engineering, Technology \& Applied Science Research, Vol. 9, No. 5, pp. 4813-4817, 2019

[13] B. Aykac, I. Kalkan, S. Aykac, Y. E. Egriboz, "Flexural behavior of RC beams with regular square or circular web openings", Engineering Structures, Vol. 56, pp. 2165-2174, 2013

[14] ABAQUS/Standard user's manual, Hibbitt, Karlson and Sorensen, Inc., 2018

[15] FIB, Model code for concrete structures, John Wiley \& Sons, 2010 